\title{
Viewpoint
}

\section{Next of kin clinics: a new role for the pathologist}

\author{
P Vanezis, S Leadbeatter
}

The loss of a close relative is one of the most distressing aspects of human experience, ${ }^{1}$ particularly when death is sudden and unexpected and apparently inexplicable. In such circumstances, neither the clinician attempting resuscitation nor the general practitioner, who may not have seen the deceased for some time, is well placed to explain to relatives how their loved one died. ${ }^{2}$ The general practitioner, however, is frequently called upon to explain the necropsy report, if available, to relatives, or to explain only the cause of death as given on the death certificate. This is clearly unsatisfactory - unless relatives receive a timely and detailed explanation of the circumstances of their loved one's death, they are frustrated, possibly feeling guilty, unable to grieve, and dissatisfied with the "medico-legal process."

The medico-legal investigation of sudden or unexpected deaths in the United Kingdom is undertaken in Scotland by the procurator fiscal and elsewhere by HM coroner. There must be few pathologists in the United Kingdom involved in such investigations who feel the process allows full opportunity for them "to bring compassion and understanding to the bereaved by means of the post-autopsy consultation with families."

Are pathologists willing or able to communicate effectively with next of kin? Many may regard such communication as difficult or stressful and best left to trained counsellors, though next of kin are well aware that pathologists are not bereavement counsellors and simply wish to meet face to face with the person who performed the necropsy and who is best placed to answer questions. Such an interview, where requested, undoubtedly assists the bereaved in their grieving ${ }^{4}$; particularly where an infant has died, it has been shown that sharing the necropsy findings with bereaved parents is a valuable part of the counselling process. ${ }^{5} \mathrm{It}$ has been said that a family will not derive any benefit from the necropsy unless they are told all the findings. ${ }^{6}$

Some may argue that the inquest is the forum for relatives to receive information and ask questions; coroners may take the view that no information should be made available in advance of the inquest. ${ }^{7}$ The majority of sudden deaths, however, will not proceed to inquest, the necropsy revealing a natural cause of death, ${ }^{8}$ and in these circumstances there can be no justification for not meeting the next of kin to explain the necropsy findings if requested. It is easy to understand the reluctance of a coroner to release information to a family before an inquest when a death has occurred in circumstances where questions of criminal or civil liability may arise. In such deaths - if not all deaths - it appears to us a missed opportunity if the pathologist were not to meet with a family before the necropsy. Such a meeting would allow the family to air any questions about the death which the pathologist may then seek to answer by appropriate investigation (families may have questions which may not be obvious to the most prescient and sympathetic pathologist) and would allow the pathologist to explain to the family precisely what the necropsy examination will entail-that it may be necessary to retain an organ such as heart or brain-or to allay any fears they may have regarding the examination or reconstitution of the body. It appears to us incongruous that in the late 20th century little advance appears to have been made in properly informing the public of the procedures of the coroner system or in gauging the public's view of its efficacy and practice: the purpose of the inquest, after all, is to "establish as many of the facts about a death as the public interest requires." It must be remembered that "the public interest" does not equate with "what is of interest to the public": there is evidence that inquests on suicides aggravate the distress of the relatives of the deceased. ${ }^{10}$

In Scotland, a fatal accident inquiry is mandatory where a death occurs in legal custody or results from an accident occurring in the course of employment. ${ }^{11} \mathrm{~A}$ recent study ${ }^{12}$ has highlighted relatives' misconceptions regarding the role of the fatal accident inquiry, their concerns over delay in holding the inquiry, and their need for more information about the death than is elicited by the inquiry: analysis of a recent scheme $^{13}$ which offered relatives the opportunity to find out in private as much as was known about their loved one's death suggested that such a private interview was more beneficial than a fatal accident inquiry.

Not all relatives will want to discuss their loved one's death in detail and that desire must be respected; a substantial number will, at some time after the necropsy, be very anxious to have such a discussion and it is important that these relatives are afforded the opportunity. Some 
relatives need time before they can face up to talking about the death; most need to find out information as soon as possible. It is undesirable to attempt to answer questions without complete information: most relatives are happy to wait several weeks or months, so long as they are kept informed of the progress of the investigation.

The organisation and setting of the interview should take into account both the need of the next of kin to receive detailed and accurate information from the pathologist and the need of the pathologist not to compromise the investigation by an understandable desire to temper with compassion answers to questions which may be impossible to answer without at least failing to alleviate distress. The question commonly asked in our experience-"Would he/she have suffered"- cannot be answered in the negative in all cases, much as one may wish to do so: it is imperative that the pathologist gives an honest but sensitively worded answer, rather than a half truth or a falsehood. A representative of the legal authority requesting the necropsy, be it procurator fiscal, coroner, or coroner's officer, should host the interview, introduce the pathologist to the relatives, and give advice on questions regarding nonmedical aspects of the investigation.
The pathologist has a central role to play in explaining the necropsy findings to next of kin, bringing them some measure of comfort: such a valuable service should be part of every pathologist's normal practice and be available to all next of kin upon request.

1 Wright Bob. Sudden death: a research base for practice, 2nd ed. Edinburgh: Churchill Livingstone, 1996.

2 Adelson LT. The forensic pathologist. "Family physician" to the bereaved. $7 A M A 1977 ; 237: 1585-8$.

3 Hirsch CS. Talking to the family after an autopsy. Arch Pathol Lab Med 1984;108:513-14.

4 Limerick. Family and health-professional interactions. Ann NY Acad Sci 1988;533:145-54.

5 Kotch JB, Cohen SR. SIDS counsellors' reports of own and parents' reactions to reviewing the autopsy report. Omega 1985-6;16:129-39.

6 Reynolds RC. Autopsies-benefits to the family. Am $\mathcal{F}$ Clin Pathol 1978;69(suppl 2):220-2.

7 Matthews P, Foreman J. Fervis on the office and duties of coroners, 11 th ed. London: Sweet and Maxwell, 1993:336.

8 Coroners Act 1988 s19 (3).

9 Lord Lane CJ. R $v$ South London Coroner ex parte Thompson (1982) 126 SJ: 625

10 Barraclough BM, Shepherd DM. The immediate and enduring effects of the inquest on relatives of suicides. $\operatorname{Br} \mathcal{F}$ Psychiatry 1977;131:400-4.

11 Fatal Accidents and Sudden Deaths Inquiry (Scotland) Act, 1976.

12 Anderson S, Leitch S, Warner S. Public interest and private grief: a study of fatal accident inquiries in Scotland. grief: a study of fatal accident inquiries in Scotland. 1995.

13 Martin L, Vanezis P. Evaluation of next of kin interview clinics in Glasgow. Edinburgh: The Scottish Office Central Research Unit, 1998. 